\title{
Translating the seventeen syllables
}

\author{
Elin Sütiste \\ Department of Semiotics, University of Tartu, \\ Tiigi 78, 50410 Tartu, Estonia \\ e-mail: elin_sytiste@hotmail.com
}

\begin{abstract}
The present paper focuses on the similarities and differences between the formal characteristics of the traditional Japanese haiku and the translated haiku, more specifically, on the relations between the 5-7-5 syllable pattern in the Japanese haiku, and the patterns of syllable arrangement employed in the translations. Due to the influence of the target culture context, there emerge certain conventions in rendering the haiku form, the appearance of which is observed in the body of 420 haiku translations, made by 7 translators. On the basis of the overall frequency of appearance, as well as in respect to individual translators, tentative characterisation is proposed as to which types of syllable arrangement patterns can be considered more formoriented than others in the context of the translated haiku, i.e., an attempt is made to mark the boundary between the "haiku-like" patterns and the "unhaiku-like" patterns.
\end{abstract}

\section{Introduction}

To start out with a cliché, translation of the haiku, it would seem, is indeed nearly impossible - its translatability is inhibited in several, it might even be said, countless ways, starting from the problems of language and ending with the nuances of meaning, such as the reverberations of kigo, the seasonal word, or hon'i, "poetic essence" that refers to the "prescribed treatment of poetic themes and their pertaining lyric sentiments" (Kawamoto 2000: 60), or the implications of kireji, the "cutting word", etc.

On the one hand, haiku has been described as "near to being a kind of cipher or code" (Kawamoto 2000: 48) — or, for that matter, Japa- 
nese classical poetry in general has been seen as resembling closely the workings of a code: "the code becomes one of the most important levels of interpretation of a poetic text" (Raud 1994: 18). On the other hand, it follows from the extreme suppressed form of the haiku that it is heavily dependent on context: "Japanese three-line poems cannot exist outside a context, and are not understood without one" (Azadovskij, Dyakonova 1991: 99). ${ }^{1}$ To bring an example from other similarly "compressed" artistic phenomena, one could parallel the haiku with minimalist music, which, presenting itself in a meagre form in praesentia, may contain sophisticated implications in absentia (Tarasti 1992: 274). A minimal(ist) form is oriented towards activating the recipient to supply the "missing" parts or context, instead of the relatively passive "skimming" through the explicitly presented text - the difference of which is well explained by Barthes's (1975: 4) notions of writerly and readerly texts. The orientation towards activating the reader is observed also in the case of the haiku: "The experienced reader of the three-line poems [haiku], participating actively in the creational process, himself provides numerous senses, existing outside the written text" (Azadovskij, Dyakonova 1991: 99). The reliance on context is probably the main argument against the translatability of the haiku, for it means that the haiku needs a competent reader, that is, one who is capable of the associations the poem directs to: "Without the traditional reader, the haiku poem is dead, since the context, i.e. the whole layer of the poetic tradition, will not be "activated" [...] Transplanting the genre of the haiku from Japanese soil into any other context means the breaking off with the tradition and the destruction of the poem" (ibid.). However, the history and popularity of haiku translation seems to, in a sense, confirm the opposite: even if we concede that the translation of the haiku cannot take place without a loss (no translation can), it does not necessarily mean that it fails altogether.

The practical impossibility of providing the non-Japanese recipient $^{2}$ with the whole accumulated context of the Japanese poetic tradition can, however, be seen also from a "brighter" perspective.

1 The quotations from languages other than English that appear in the present article have been translated by the author, unless otherwise indicated.

2 However, today even Japanese readers may need "translations" of classical Japanese texts or explanations of poetic traditions, ef Donald Keene's opinion expressed in his preface to Bashō's travel diary Oku no Hosomichi [The Narrow Road to Oku]: "The problem of translating Oku no Hosomichi into modern Japanese is almost as great as translating it into a European language" (Bashō 1996: 9). 
Andrew Chesterman, reflecting upon what he calls the "supermemes of translation", compares the viewpoints of equivalence and untranslatability in the following manner:

Translation is, after all, a form of language use; and from this point of view nothing is untranslatable: that is, everything can be translated somehow, to some extent, in some way - even puns can be explained. Semiotically speaking, we could say that communication succeeds to the extent that the message decoded and interpreted by the receiver overlaps with that sent by the sender. Whereas the equivalence supermeme focuses on the overlap, the untranslatability supermeme focuses on the non-overlapping part of the message: each supermeme then assumes that the part it sees is actually the whole picture. (Chesterman 2000: 12)

For a practicing translator, the long-disputed idea of untranslatability is indeed of little help: therefore, instead of focusing upon what cannot be done, translators have often tried to draw the readers' attention to what can. In our present context of haiku translations, where the parts of a message overlapping between the sender and the receiver indeed often seem a great deal smaller than those not overlapping, various translators, instead of "explaining" the original poems, have left this task quite explicitly to the readers. For example, Makoto Ueda in his work "Bashō and His Interpreters" proposes the readers not to just read his translations, but to create their own interpretations:

Ideally, however, individual readers should attempt their own translations according to their own tastes and preferences. [...] I have refrained from making my own comments on the meaning of the poem, so that individual readers can, like spectators of an abstract painting, freely speculate on the implications of the work before them. (Ueda 1991: 11)

As the starting point for a reader's journey towards the poem, Ueda provides him with "the original Japanese poem in roman letters and a word-for-word translation", and, in addition, "when a Japanese word seems to call for an explanation, I have put a note in the section that follows" (ibid.). In other words, Ueda presents his reader only the pieces of a puzzle, but he leaves it to the reader to put the picture togetherassuring at the same time that a large part of the pleasure of the game is in getting different pictures. Much the same is done also by Toshikaru Oseko, who, in the section about his method of translation, repeatedly conveys his intention to provide as "correct information" as possible, e.g.: "I have tried to translate the text as literally as possible", "I have tried to stick to the original word order if possible", "I have inserted many "kanji" (Chinese characters) to give you the correct information" (Oseko 1990: 
section 2). Thus, stressing his wish to be as "correct" about the original material as possible, he is trying not to impose his reading or his combination of the original elements on the reader.

As any artistic work, haiku is a complicated whole with different levels and elements, and therefore, in translating the haiku (similarly to any other translation), the question of dominant becomes important that is, the question about the element a translator considers to be the most important to transfer. In analysing a translation, the discernment of the dominant helps us to explicate the method of translation, to provide explanation for the lost or added elements, for the functions of elements in the structure of the text, and their correspondence to the overall poetic model (see Torop 1995: 103).

Ideas about how one should translate a haiku vary enormously, depending on whether haiku is conceived of primarily as a poetic form, or as a Zen experience that is attached to its form rather accidentally, or as something third. In discussing the forms of verse translation and the translation of verse form, Holmes (1988: 26-27) discerns the following four traditional strategies in the translation of verse forms:

1. mimetic, where the original form is preserved

2. analogical, where a corresponding form of the target culture is employed

3. organic, where the semantic material of the original poem is taken as a starting point, which is then allowed "to take on its own unique poetic shape as the translation develops"

4. deviant or extraneous, where the resultant form is "in no way implicit in either the form or the content of the original".

In the history of haiku translation, several strategies have been employed: for example, the beginnings of haiku translation into English saw abundant cases of analogical strategy, the effect of which is the "naturalization" of a foreign form. Mimetic strategy, on the other hand, has been an issue of heated debates already for decades - both in the case of haiku translation and in the case of the original haiku composed in English. In respect to using 17 syllables $^{3}$ also in haiku composed in English, however, there shows a tendency not to use the mimetic strategy: according to Swede (2000: 13), his studies carried out in the 1980 and

3 Although in discussing Japanese poetry, it would be more accurate to use the term 'mora' instead of 'syllable', in the context of this article this distinction is not of foremost relevance: translations from a mora-counting language into languages that do not count moras inevitably have to change or adapt the source-text form. Very often, the unit 'mora' is substituted with the unit 'syllable' in translations. Thus, in order to avoid unnecessary complications, our discussion will use the term 'syllable' also when referring to Japanese haiku. 
1996 reveal that, starting from the 1960 s, $80 \%$ of the haiku published in anthologies and periodicals have less than seventeen syllables. On the other hand, in the case of original haiku composed in Estonian, it appears that the observance of the 5-7-5 syllable pattern is followed almost exclusively (Lindström 1999: 32). In respect to the translated haiku (although on a much smaller scale), the results of a study concerning 32 translations into English of a single haiku by Matsuo Bashō (Sütiste 2001) display a similar tendency: only four translations retained the original number of syllables (in this case, nineteen), the average number of syllables being 15 .

The phenomenon of the translated haiku incorporates features that have originated in the source culture as well as in the target culture: for example, in the case where a translation retains the 5-7-5 syllable pattern (mimetic translation), due to the differences in language prosody, the result can only be similar, not identical in form with the Japanese haiku. Japanese poetry counts, strictly speaking, moras (not syllables; see also footnote 3 ) that may contain no more than one consonant, whereas, for instance, English monosyllabic words include also such cases as bright or skirt. This difference results in English carrying more information per syllable than Japanese, which together with other factors indicates that "using the 5-7-5 form does not necessarily provide an analogous condition for writing haiku in English". Similarly, Mart Mäger (1979: 130) observes that the first obstacle to the spreading of haiku as a form is the difference between languages: the information a syllable carries is not equal in different languages. Thus, English and Russian translations do not usually follow the number of syllables provided by the original haiku. Estonian, on the other hand, seems to accommodate the 17 syllables, corresponding to the haiku-like amount of content. This phenomenon is similar to the problems that arise in transplanting other poetic forms and metres into such cultural-linguistic contexts that are different from those of the source culture. For example, Mihhail Lotman and MariaKristiina Lotman (2000: 139-140) describe the problems related to the rendering of the classical versification systems: during the 19th century, Estonian poetry followed the German models, where quantitative verse was rendered according to accentual principles (i.e., long syllable was represented by an accented syllable, short syllable by an unaccented syllable). In the 20th century, it was found that

4 Imaoka, Keiko 1995. Forms in English Haiku. http://www.lowplaces.net/ keiko_forms.html 
classical quantitative verse could, in principle, be rendered quantitatively also in Estonian; however, such attempts were not too successful as the poets, having started out following the quantitative principle, tended to "slip back" into the older and more natural syllabic-accentual patterns. Likewise, in the case of haiku, it is observable that in the translation, source culture features interfere with target culture features. For one, a translated haiku may strive to retain the original number of syllables, at the same time adding such target culture characteristics as word accent, or the translation may deviate from the original number of syllables since the translator finds that the source culture form is not suitable for transmitting the content either because of the strategy adopted by the translator, or because the informational content of the seventeen syllables in Japanese is not comparable to that in another language, or because it is considered to be most important in haiku translation to transmit the "haiku spirit" or a Zen experience that need not retain the rigid 5-7-5 syllable structure ${ }^{5}$, etc.

In the following, however, I will maintain the following position: disregarding what kind of experience it conveys, haiku will here be regarded as a poetic form with a certain structure. ${ }^{6}$ With this view of haiku in mind, it is held that to be regarded as a "haiku-like" translation, it has to possess some characteristics that would be perceived as "haiku-like". 7 However, the boundary between a "haikulike" translated haiku and an "un-haiku-like" translated haiku is not very clear. Although numerous studies have been carried out and heated debates have been held on the subject of haiku in languages other than Japanese (especially English), in the case of the translated haiku, main attention has been concentrated upon the question of correspondence between the content and the form adopted, not so much upon the degree of similarity/dissimilarity between the original form and the translation form. The following will be an attempt to find some clarity in this issue, and this will be done by considering once

${ }^{5}$ Cf Y. Yamada-Bochynek (1985: 437): "Syllable counting [...] is one of the major concerns in establishing haiku in English. It seems, however, more important to have a haiku cadence, which is not the product of a mechanical 5-7-5 count but more necessarily the result of the expression of a "haiku-moment"".

"It should be noted that under "haiku" as a poetic form the traditional haiku is presupposed, not versions of modern haiku that may deviate from the classical structure.

${ }^{7}$ In principle, the reverse is also possible: the translation may look like a haiku and count as one, even if the source text has not been a haiku. 
more the long-debated subject of the number of syllables and lines in haiku translation. Thus, I will be dealing with the translation of haiku form rather than content, and I will occupy myself only with the issue of the number of syllables and lines, and will not include the questions of kireji, the "cutting word" or kigo, the seasonal word, which could, at least to some degree, be categorised under form issues as well.

\section{Syllables}

While the 5-7-5 syllable pattern is, no doubt, one of the strongest markers of the form "haiku", it is not always regarded as the most essential feature to be transmitted. This becomes evident when we look at the actual translations. For the purposes of the present work, I assembled a corpus of 420 haiku translations (all together 1260 lines) made by 7 different translators (including two non-English sets of translations, by Masing and Markova, into Estonian and Russian, respectively), 60 translations by each translator. ${ }^{8}$ The corpus was assembled with an idea to ensure a degree of variety, i.e. among the translators, there are scholars of Japanese literature (e.g., K. Yasuda), professional translators of Japanese literature (e.g., V. Markova), poets (e.g., P. Donegan), a scholar who translated haiku out of his personal interest, not so much for publishing (U. Masing), etc. The majority of translations are of Bashō — the most renowned and the most translated haiku poet. However, also other poets are included, and the only translators, who are not represented by any of Bashō's haiku, are P. Donegan and Y. Ishibashi - their texts are assembled from their volume of translations of a woman haiku-poet Chiyo-jo. The sets of translations have not been selected by any specific criteria: the texts were assembled by taking the first sixty translations from the beginning of their appearance in each respective book or selection. Within this corpus, some translators try to preserve the original 5-7-5 syllable pattern, some try to retain occasionally the overall number of 17 syllables, still others do not care much for neither - it appears that great differences exist in the preferences of individual translators: for example, while Masing retains the 5-7-5 syllable pattern in the fifty-

${ }^{8}$ These sets of translations are assembled from: Markova 1973: 45-65; Masing 1997: 7-39; Bownas, Thwaite 1972: 111-119; Yasuda 1985: 183-195; Blyth 1984: 106-130; Keene, in Bashō 1996: 19-171; Donegan, Ishibashi, in Yamane 1996: 27147. 
five translations out of sixty (an instance of the employment of the mimetic startegy), Donegan, Ishibashi, on the other hand, have no translations adhering to this type of syllable organization. The observance of the 5-7-5 syllable pattern is described in Table 1, with the middle column showing the number of translations following the 5-7-5 syllable pattern (per the set of sixty translations by each translator), and the last column showing the same number in percentages:

Table 1. The observance of 5-7-5 syllable pattern by individual translators.

\begin{tabular}{|l|c|c|}
\hline & $5-7-5$ & $\%$ of $5-7-5$ \\
\hline Masing & $55 / 60$ & 92 \\
\hline Yasuda & $31 / 60$ & 52 \\
\hline Keene & $18 / 60$ & 30 \\
\hline Blyth & $2 / 60$ & 3 \\
\hline Bownas, Thwaite & $2 / 60$ & 3 \\
\hline Markova & $2 / 60$ & 3 \\
\hline Donegan, Ishibashi & $0 / 60$ & 0 \\
\hline
\end{tabular}

It might be thought that if translators in trying to adhere to the 5-7-5 pattern cannot manage to organize the syllables exactly in this fashion, then they are still likely to group the syllables somehow differently to maintain at least the overall number of seventeen syllables. However, as we see from Table 2, the adding of other 17-syllable translations to the ones that follow the 5-7-5 syllable pattern, does not change much in the general picture.

Table 2. The observance of the 17 syllables.

\begin{tabular}{|l|c|c|}
\hline & 17 syl. & \% of 17 syl. \\
\hline Masing & $56 / 60$ & 93 \\
\hline Yasuda & $31 / 60$ & 52 \\
\hline Keene & $22 / 60$ & 37 \\
\hline Blyth & $8 / 60$ & 13 \\
\hline Bownas, Thwaite & $4 / 60$ & 7 \\
\hline Markova & $3 / 60$ & 5 \\
\hline Donegan, Ishibashi & $1 / 60$ & 2 \\
\hline
\end{tabular}


Tables 1 and 2 give us some general information in respect to the individual translators' preferences: thus we can say that, for example, Masing is very much oriented towards retaining the original syllable pattern, while Donegan, Ishibashi and Markova are not, and while other translators are left somewhere in between. Also, when compared to the before-mentioned studies made by Swede (see above), it appears that, together, the translators into English display a similar percentage of not observing the number of seventeen syllables (78\%) as the haiku poets of Northern America (80\%).

However, the above tables fail to describe other formal features that may also be relevant in the case of translated haiku. Judging by the existing translations, it seems unreasonable to expect that each and every translation follow the exact syllable pattern of the original. What is often done instead is that translators try to follow a general idea of haiku as a short poem that is organized into three symmetrically balanced lines. I regard the above characterization as essentially pertaining to the approximation in form of a translated haiku to the Japanese original. "Symmetrically balanced" is an important keyword: there is no use in observing 17 syllables, if we organize them into lines of, say 9-5-3 (which is, incidentally, an actually existing example ${ }^{9}$ ) - the outcome will probably be perceived as an approximation of haiku form, but not a very close one. It follows then that it does not only matter how many syllables are there in one line or all together, but it is the relation between the number of syllables in one line and another that is important. Since there are translators who do not observe the exact 5-7-5 or the total of seventeen syllables very keenly and yet their translations can be regarded as "haiku-like", it seems that there has to be left space for the "acceptable" deviations that do not affect the general perception of the translation form as that of a haiku. Thus, our next step will be to look into the matter of lines in haiku translations.

How thrilling!

Haiku by Bashō; translated by R. H. Blyth (Blyth 1984: 114). 


\section{Lines}

Whether rendering the form of haiku by following an exact number of syllables or not, it is true that the majority of haiku translations follow the pattern of three lines. However, this matter has not passed without disputes either: not all translators have seen the three lines as the main option in haiku translation. For example, there are translators who favour translating haiku into one line, mainly on the grounds that the original Japanese haiku were written in monolinear form. Besides monolinear form, attempts have been made to translate haiku into two and four, also five lines e.g.:

Nothing in the cicada's voice

Gives token of a speedy death. ${ }^{10}$

A black crow

Has settled himself

On a leafless tree

Fall on an autumn day. ${ }^{11}$

Busy cicadas chirp and cry

On brilliant August days,

Zzurr, zzurr-

In this ignorant haze

They think they'll never die. ${ }^{12}$

The choice to translate haiku into the form of one, three, or any other number of lines, is a matter of choosing a poetic model a translator wishes to employ (cf. Ueda 1991: 10): “each translator's style seems to have been determined by two main factors: his conception of the basic nature of hokku and his choice of English poetic models"). In Gideon Toury's words, it has to do with the striving towards the prospective acceptability of the translated text in the target culture:

Being members of the target culture, or tentatively assuming the role of ones, translators are more or less aware of the factors which govern the acceptability of texts and textual-linguistic features in that culture, or a certain sector thereof. To the extent that they choose to subject themselves to these factors and resort to the appropriate translation strategies, the act itself is executed

\footnotetext{
${ }^{10}$ Haiku by Bashō; translated by B. H. Chamberlain (Ueda 1991: 10).

${ }^{11}$ Haiku by Bashō; translated by N. Yuasa (Toury 1993: 24).

${ }^{12}$ Haiku by Bashō; translated by F. L. Huntley (Ueda 1991: 11).
} 
under the initial norm of acceptability; whether the end-product will indeed be admitted into the target system or not. (Toury 1993: 16)

In the case of the first haiku translations into English at the end of the 19th and the beginning of the 20th century, there were attempts namely to relate haiku to some literary forms already known in the target culture; thus, Japanese haiku was sometimes paralleled with epigram, as becomes evident already from such titles as B. H. Chamberlain's "Bashō and the Japanese epigram", or William Porter's anthology of translations A Year of Japanese Epigrams, etc. (Kawamoto 2000: 47; Yasuda, Kuriyama 1983: 80). A similar tendency has been observed in the attempts to translate haiku also into other cultures, for example, Chinese: for Chinese readers, a traditional poem would minimally consist of at least four pentasyllabic lines, hence, "from the standpoint of this tradition, a haiku will no doubt seem like a bicycle with a missing wheel" (Kawamoto 2000: 164). Thus, the following haiku by Bashō:

\author{
natsukusa ya \\ tsuwamono domo ga \\ yume no ato
}

The summer grasses-

Of brave soldiers' dream

The aftermath. ${ }^{13}$

has been rendered into Chinese in the form of a pentasyllabic quatrain, the approximation of which is the following English translation:

\begin{abstract}
The lord's flourishing lands
once served as the field for bloody battle;

Looking on them now, the summer grass is lush, and fame is just a fleeting dream. ${ }^{14}$
\end{abstract}

\title{
Syllables in three lines
}

However, as mentioned before, the majority of haiku translations follow the three-line pattern nowadays. Similarly to other variants, this choice also has its justification: thus, for example, Oseko preferres translating the haiku into three lines "with the original 5-7-5 syllable count in mind" (Oseko 1990), and Ueda bases his translations on the

\footnotetext{
${ }^{13}$ Translated by D. Keene (Bashō 1996: 87).

${ }^{14}$ Original translation by Peng Enhua, here quoted from Kawamoto 2000: 165.
} 
interpretation of haiku as a "three-phrase poem" (Ueda 1991: 11) both arguments rather naturally yield a three-line poem in English. On the other hand, while the preference in favour of three lines certainly reflects the attempt to follow the poetic devices of the source culture, it should be also remembered that, by now, haiku has become an acceptable poetic form also in the West, so that there is no need to "justify" its three-line form in the target culture's terms anymore, and a large part of haiku translations take it as a natural model to rely on.

Also, in the corpus used in the present work, ${ }^{15}$ all translations follow namely the three-line model. However, the ways three lines are organized are rather diverse, and we could say the patterns used fall into two large groups, symmetrical and asymmetrical patterns.

\section{Symmetrical patterns}

Patterns of syllable organization are considered symmetrical in the following cases:

\section{1. "Exact" symmetry}

1a. "Exact" symmetry $\mathrm{A}<\mathrm{B}>\mathrm{A}$,

where $A$ marks the equal number of syllables for the first and the last lines, and B marks the middle line, with B containing more syllables than A (e.g., 6-8-6; 4-7-4, etc.).

Example:

In its eye 3

the far-off hills are mirrored - $\quad 7$

dragonfly! ${ }^{16} \quad 3$

In the present corpus, this type of "exact symmetry" is used extensively: not taking into account translations that follow the 5-7-5 syllable pattern, 78 translations are organized according to this pattern.

${ }^{15}$ Since it is the aim of the present work to explore the significance of some formal features in the translation of haiku, and since the use of 5-7-5 syllable pattern is by definition one of the primary (formal) characteristics of haiku so that a translation following this pattern can be said to already observe the formal haiku structure, then in the following section concerning syllable arrangement patterns those translations that follow the 5-7-5 syllable pattern have been excluded from further observation as already representing the haiku form, and therefore not needing in further clarification (within the limits of the present discussion, of course).

${ }^{16}$ Haiku by Issa; translated by H. G. Henderson (Keene 1996: 431). 
1b. "Exact" symmetry $A>B<A$,

which is the reverse of the previous type. A marks the equal number of syllables for the first and the last lines, and B marks the middle line, with B containing less syllables than A.

Example:

"Country bumpkin" 4

People call me, - 3

How cold it is! ${ }^{17}$

This type of symmetry is used much less than the previous one: there are only 15 translations that follow this model.

1c. "Exact" symmetry AAA,

where A marks the equal number of syllables in all three lines. ${ }^{18}$

Example:

I will bind iris

Blossoms round my feet - 5

Cords for my sandals! $!^{19}$

This type is not used extensively at all: there are only 6 examples of its use in the present corpus.

\section{2. "Relative" symmetry}

I propose to see as belonging into this category such haiku translations which are not strictly symmetrical, but which nevertheless leave a general impression of symmetry.

2a. "Relative" symmetry $\mathrm{A}<\mathrm{B}>\mathrm{C}$,

where $\mathrm{A}$ and $\mathrm{C}$ mark the first and the last line, respectively, and where $\mathrm{A}$ and $\mathrm{C}$ are of unequal length, and where $\mathrm{B}$ marks the middle line that contains more syllables than A and C.

Example:

To bird and butterfly

it is unknown, this flower here:

8

the autumn sky. ${ }^{20}$

4

${ }^{17}$ Haiku by Issa; translated by R. H. Blyth (Blyth 1984: 352).

${ }^{18}$ Of course, it is debatable whether this type can be considered symmetrical at all, since the axis is not differentiated from the other two lines.

${ }^{19}$ Haiku by Bashō; translated by D. Keene (Bashō 1996: 71).

${ }^{20}$ Haiku by Bashō; translated by H. G. Henderson (Keene 1996: 384). 
This is the type of "relative approximation" to the 5-7-5 syllable organization of the haiku, and one that is used the most extensively in the present corpus: there are 100 examples (almost one fourth of the entire corpus) of the usage of this model.

2b. "Relative" symmetry A $>\mathrm{B}<\mathrm{C}$,

which is the reverse of the previous type. A and $\mathrm{C}$ mark the first and the last line, respectively, while $\mathrm{A}$ and $\mathrm{C}$ are of unequal length, and $\mathrm{B}$ marks the middle line that contains less syllables than A and $\mathrm{C}$.

Example:

the sandal maker 5

has come - 2

the first cherry blossoms ${ }^{21} \quad 6$

This type is used rarely: only two translators of the present corpus have used it, 12 times all together.

\section{Asymmetrical patterns}

Among asymmetrical patterns belong the following groups:

\section{Type AB}

1a. Asymmetry AAB,

where A marks the first two lines of equal length, and B marks the third line of different length than that of the first two lines.

Example:

A falling flower, thought I, $\quad 7$

Fluttering back to the branch - $\quad 7$

Was a butterfly. ${ }^{22} 5$

This type of asymmetry has been exploited rather extensively, by all translators, all together 39 times. However, within this type also variations occur: in the first subgroup, A is longer than B (e.g., 8-8-6), and in the second, B is longer than A (e.g., 6-6-8). Although the patterns of the first subgroup are used by six translators, and the

${ }^{21}$ Haiku by Chiyo-ni; translated by P. Donegan and Y. Ishibashi (Donegan and Ishibashi 1998: 111).

${ }^{22}$ Haiku by Moritake; translated by K. Yasuda (Yasuda 1985: 183). 
patterns of the second subgroup only by three of them, the translators who follow the patterns of the first subgroup most often, do the same also in the case of the second subgroup.

\section{1b. Asymmetry ABB,}

where A marks the first line that is of different length than that of $B$, and where B marks the second and the third line that are of equal length.

\section{Example:}

On a bare branch 4

A rook roosts: 3

Autumn dusk. $^{23} \quad 3$

Although a little less than the previous type, this one has been used also rather often, 27 times, and by the majority of translators. This type allows also two variants: one where A is longer than B (e.g., 7-66), and the other where B is longer than A (e.g., 6-7-7). The first type has been employed less, 8 times by 3 translators. The second type has been of more use: five translators have followed this pattern, all together 19 times.

\section{Type ABC}

\section{2a. Type $\mathrm{A}>\mathrm{B}>\mathrm{C}$,}

where A represents the first line, which is longer than $\mathrm{B}$, the second line, which, in its turn, is longer than the third line, $\mathrm{C}$

Example:

$\begin{array}{lr}\text { Making the uguisu its spirit, } & 10 \\ \text { The lovely willow-tree } & 6 \\ \text { Sleeps there. }^{24} & 2\end{array}$

The type is not very popular with translators, although there are examples of this. In the present corpus, this syllable organization has been used by four translators, all together 13 times, to a large extent by Blyth and Donegan, Ishibashi.

${ }^{23}$ Haiku by Bashō; translated by G. Bownas and A. Thwaite (Bownas, Thwaite 1972: 111).

${ }^{24}$ Haiku by Bashō; translated by R. H. Blyth (Blyth 1984: 111). 
2b. Type $\mathrm{A}<\mathrm{B}<\mathrm{C}$,

which is the reverse of the previous, and where A represents the first line that is shorter than the second line B, which, again, is shorter than $\mathrm{C}$, the third line.

\section{Example:}

fortune straw - 3

even the dust 4

looks beautiful this morning ${ }^{25} \quad 7$

This type is used more often than the previous one, being employed by three translators, 19 times in total.

\section{Marker of the 5-7-5 syllable pattern: 5-7-x or $x-7-5$,} where $x$ marks the variable number of syllables in the first or in the last line, respectively. This is another significant element in a translated haiku to mark the "haiku-ness" of the translation: the retaining of a "part" of the prototypical 5-7-5 syllable pattern, in the form of 5-7 (in the first and the second line) or 7-5 syllables (in the second and the third line). ${ }^{26}$

Examples:

$5-7-x$

If only we could

Add a handle to the moon

It would make a good fan! $!^{27}$ $x-7-5$

$5 \quad$ Spring rain: 2

$7 \quad$ Telling a tale as they go, 7

6 Straw cape, umbrella. ${ }^{28} \quad 5$

${ }^{25}$ Haiku by Chiyo-jo; translated by P. Donegan and Y. Ishibashi (in Yamane 1996: 41).

${ }^{26}$ It could be argued that while the usage of either 5-7-x or $x-7-5$ syllable combination in a translation is regarded here as a device for marking the form of the original haiku, the same could also be stated about the usage of, for example, 5-5 or, indeed, any instance of a 5- or a 7- syllable line. However, while in principle this may be true, it is considered here that the combination of 5-7 or 7-5 syllable lines in a translation is closer to the original haiku form than other possbile combinations with a 5- or 7-syllable line, since the former include two different markers (a 5-syllable line and a 7-syllable line) of the haiku form instead of one.

${ }^{27}$ Haiku by Sōkan; translated by K. Yasuda (Yasuda 1985: 183).

${ }^{28}$ Haiku by Buson; translated by G. Bownas and A. Thwaite (Bownas, Thwaite 1972: 119). 
This device is observable in the case of five translators, however, two of these are especially telling: while other translators' use of the device is minimal, Yasuda and Keene both employ it 16 times.

All the types described above, together with the instances of 5-7-5 syllable pattern, as well as the appearances of 5-7-x and $\mathrm{x}-7-5$, are presented in Table 3. The table displays the number of instances an individual pattern is employed by a particular translator, within the body of sixty translations per each translator (if in the case of a particular translator there were no appearances of a pattern, the respective cell was left unfilled in order to convey its absence more conspicuously). The first row of patterns presents the number of appearances of the pattern 5-7-x or x-7-5, which forms a part of other patterns, ${ }^{29}$ and is therefore not characteristic of an entire translation. This row is marked in bold to avoid its confusion with other types that are characteristic of entire translations. It should also be noted that the type $\mathrm{A}<\mathrm{B}>\mathrm{A}$ includes all instances of "strict symmetry" of this type, except the instances of the prototypical pattern 5-7-5.

Table 3. Instances of syllable arrangement patterns in the translated haiku.

\begin{tabular}{|l|c|c|c|c|c|c|c|c|}
\hline Patterns & Masing & Yasuda & Keene & Markova & $\begin{array}{c}\text { Bownas, } \\
\text { Thwaite }\end{array}$ & Blyth & $\begin{array}{l}\text { Donegan, } \\
\text { Ishibashi }\end{array}$ & Total \\
\hline $\mathbf{5 - 7 - x} / \mathbf{x}-\mathbf{7 - 5}$ & $\mathbf{2}$ & $\mathbf{1 6}$ & $\mathbf{1 6}$ & $\mathbf{1}$ & $\mathbf{2}$ & & & $\mathbf{3 7}$ \\
\hline $5-7-5$ & 55 & 31 & 18 & 2 & 2 & 2 & & 110 \\
\hline $\mathrm{A}<\mathrm{B}>\mathrm{A}$ & 2 & 7 & 15 & 29 & 14 & 6 & 5 & 78 \\
\hline $\mathrm{A}<\mathrm{B}>\mathrm{C}$ & 2 & 19 & 24 & 21 & 11 & 10 & 13 & 100 \\
\hline $\mathrm{AAB}$ & 1 & 2 & 1 & 4 & 7 & 10 & 15 & 40 \\
\hline $\mathrm{ABB}$ & & 1 & & 2 & 11 & 6 & 7 & 27 \\
\hline $\mathrm{AAA}$ & & & 1 & 1 & 2 & 1 & 1 & 6 \\
\hline $\mathrm{A}>\mathrm{B}>\mathrm{C}$ & & & 1 & & 2 & 6 & 4 & 13 \\
\hline $\mathrm{A}>\mathrm{B}<\mathrm{A}$ & & & & 1 & 6 & 3 & 5 & 15 \\
\hline $\mathrm{A}<\mathrm{B}<\mathrm{C}$ & & & & & 5 & 8 & 6 & 19 \\
\hline $\mathrm{A}>\mathrm{B}<\mathrm{C}$ & & & & & & 8 & 4 & 12 \\
\hline
\end{tabular}

${ }^{29}$ As the pattern 5-7-x and $\mathrm{x}-7-5$ may naturally form a part of the 5-7-5 syllable pattern, the latter is excluded from the discussion here. Apart from 5-7-5, the pattern 5$7-\mathrm{x}$ and $\mathrm{x}-7-5$ can, in principle, appear within all the types except $\mathrm{AAA}, \mathrm{A}>\mathrm{B}<\mathrm{A}$, $\mathrm{A}>\mathrm{B}<\mathrm{C}$. 
The above-described discernment of types gives us a tentative overview of which kinds of syllable organization are preferred and which ones are avoided in haiku translations in general. Thus, we can say that, within the present corpus, the least followed pattern is AAA with the lines of equal length, and the next least used patterns are $A>B<C$ and $\mathrm{A}>\mathrm{B}>\mathrm{C}$. On the other hand, the most exploited syllable arrangement model (apart from 5-7-5) is $\mathrm{A}<\mathrm{B}>\mathrm{C}$, that is here named "relative asymmetry" (type 2 a above), where the middle line is longer than the first and the last lines. Although this type does not follow the original haiku form exactly, it still transmits an impression of a "haiku-like" form.

The forms of syllable organization reveal significant information about the translation dominants of individual translators. The observance of the prototype model of haiku, i.e. the syllable pattern of 5-75 , of course gives us the first understanding about the degree a translator tries to retain the form of haiku: from the first glance it becomes obvious, for example, that Masing is extremely formoriented, ${ }^{30}$ as fifty-five of his sixty translations follow the 5-7-5 model. On the other hand, we can also see that, for example, Donegan, Ishibashi or Blyth or Markova are evidently not oriented primarily towards rendering the form of haiku, which means that their dominant lies somewhere else. However, the observance of neither the 5-7-5 syllable pattern nor the overall number of seventeen syllables does not reveal the more specific degree to which individual translators try to convey the haiku form, while the possible patterns of syllable organization inform us, e.g. that while a translator may not follow the exact haiku form, he/she may try to approach it as frequently as possible by using the type of "relative symmetry" $\mathrm{A}<\mathrm{B}>\mathrm{C}$. The frequency of appearance of different patterns explicates also which patterns are regarded by translators as more similar to haiku than others: from the above-given information, we can guess that the form $\mathrm{ABB}$ is considered more appropriate for rendering a haiku than, for instance, the form AAA. The study of this corpus also confirms one's intuitions concerning translation strategies: for instance, we can infer that the more different types of pattern organization a translator uses, the less determined he/she is in the choice of a specific form in which to render a haiku.

${ }^{30}$ Cf U. Masing's own opinion: "In Estonian, it [a haiku] could be written also as in $4+6+4,3+5+3$, if there is no wish to write in $5+7+5$, [but] all kinds of "free" forms are not haiku. A sonnet in vers libre is not a sonnet!" (Masing 1989: 1000). 
Since the adherence to the 5-7-5 syllable pattern is the primary "key" to judging an individual translator's orientation towards translating the form of the haiku, it can also provide us with an imaginary axis or scale, with Masing occupying its one extreme end and Donegan, Ishibashi the other. Towards Masing's end we can also place Yasuda and Keene who both show a strong tendency to follow the 5-7-5 pattern, as well as the combinations of 5-7-x and x-7-5.

Yasuda and Keene, who (next to Masing) follow the 5-7-5 syllable pattern more often than others, use almost exclusively the "relative symmetry" pattern $\mathrm{A}<\mathrm{B}>\mathrm{C}$ and the "strict symmetry" pattern $\mathrm{A}<\mathrm{B}>\mathrm{A}$ in their other translations. They also display a marked tendency to employ the combinations 5-7-x or x-7-5, e.g. in the patterns 5-7-6 or 4-7-5: it appears then that although a large part of their translations does not follow the 5-7-5 syllable pattern or the overall number of 17 syllables, many of their translations appear marked as "haiku". The same feature may also be seen in the cases of some other translators, but then only minimally (1-2 times); however, with both Yasuda and Keene it is observable 16 times.

We could thus say that these three translators (Masing, Yasuda, Keene) constitute the more form-oriented group among the present corpus. However, the other end of the imaginary scale is "fuzzier", mainly because the tendencies towards one or another type are not as clear-cut as with the more form-oriented group.

Next to the translators who display a strong tendency towards following the 5-7-5 pattern, there are others who do not display such tendency: Markova; Bownas, Thwaite; Blyth (all of them use this pattern two times), and Donegan, Ishibashi (do not use at all). Blyth and Donegan, Ishibashi use the "relative symmetry" pattern $\mathrm{A}<\mathrm{B}>\mathrm{C}$ to some extent (10 and 13 times, respectively), but to about the same degree they observe also the pattern $\mathrm{AAB}$ that is used less by other translators. Compared to these two types, their adherence to the "strict symmetry" type $\mathrm{A}<\mathrm{B}>\mathrm{A}$ is weaker, approximately the same as their observance of the types $\mathrm{ABB}, \mathrm{A}>\mathrm{B}>\mathrm{C}, \mathrm{A}<\mathrm{B}<\mathrm{C}, \mathrm{A}>\mathrm{B}<\mathrm{C}$, and also $\mathrm{A}>\mathrm{B}<\mathrm{A}$ - all of which appear rarely (or not at all) with Masing, Yasuda and Keene. It follows quite naturally that we can place Blyth rather safely together with Donegan, Ishibashi at the "liberal" end of the imaginary scale.

Now, while we have more or less cleared the issue with five of the translators, there are still translators who are left in-between: Markova and Bownas, Thwaite. Neither Markova nor Bownas, Thwaite follow the 5-7-5 syllable pattern very keenly: similarly to Blyth, they have 
only two translations that adhere to this model. However, differently from Blyth, their other translations display a tendency towards these models that are used by the more form-oriented translators, rather than those used by Blyth and Donegan, Ishibashi: both follow extensively the patterns of "strict symmetry" $\mathrm{A}<\mathrm{B}>\mathrm{A}$ and "relative symmetry" $\mathrm{A}<\mathrm{B}>\mathrm{C}$. However, here also appear differences: for one, Bownas, Thwaite use the type $\mathrm{ABB}$ as many times as the type of "relative symmetry" $\mathrm{A}<\mathrm{B}>\mathrm{C}$ - this seems to bring him closer to the translation preferences of Blyth and Donegan, Ishibashi; besides, his translations feature all together eight types of syllable organization out of nine. Markova, on the other hand, follows the two types - "strict symmetry" $\mathrm{A}<\mathrm{B}>\mathrm{A}$ and "relative symmetry" $\mathrm{A}<\mathrm{B}>\mathrm{C}$ - almost to the exclusion of other types: while in the case of Bownas, Thwaite the relation of these two types to the other types used is $25: 35$, in the case of Markova the relation is $50: 10$. Since the variety of types that Markova uses is also smaller than that of Bownas, Thwaite, we may conclude that Markova is considerably closer to the form-oriented group, while Bownas, Thwaite are closer to Blyth and Donegan, Ishibashi.

When comparing the results obtained by simply looking at the observance of the 5-7-5 syllable pattern and the overall number of 17 syllables, to the results of the analysis of syllable arrangement patterns, there appear some changes. While Masing, Yasuda and Keene have retained their positions as the most form-oriented translators, and Donegan, Ishibashi have retained the position of the most "liberal" translators, more clarity has been acquired in respect to the "in-between cases", i.e. Bownas, Thwaite, Blyth and Markova. Judging by the analysis of syllable arrangement patterns, Blyth and Bownas, Thwaite tend to render the haiku form with about the same liberty as Donegan, Ishibashi. Markova, on the other hand, compared to the previous results, appears to "have become" more formoriented - although, in general, she does not render haiku in their original 5-7-5 syllable pattern or in the overall number of 17 syllables, her translations are still rather form-oriented, which is the result of observing the patterns of "exact symmetry" $\mathrm{A}<\mathrm{B}>\mathrm{A}$ and "relative symmetry" $\mathrm{A}<\mathrm{B}>\mathrm{C}$.

Thus, it could be tentatively suggested that a translation, in order to mark the haiku form, does not necessarily have to follow the 5-7-5 syllable pattern or the overall number of 17 syllables. It might be enough for a translated haiku to prefer some type of syllable arrangement over another to be considered haiku-like. It appears that the 
syllable patterns more suitable for marking the form of translation as that of a haiku (of course, besides the 5-7-5 syllable pattern) are the "relative symmetry" pattern $\mathrm{A}<\mathrm{B}>\mathrm{C}$ and the "exact symmetry" pattern $\mathrm{A}<\mathrm{B}>\mathrm{A}$, and to a lesser extent also the patterns $\mathrm{AAB}$ and $\mathrm{ABB}$ - the latter could be regarded as the border-cases between the "haiku-like" and the "un-haiku-like" translations.

In the context of the present study, it may only be assumed that there exist specific reasons for the preferences towards some syllable arrangement patterns over the others: for instance, a haiku may be regarded as "something less" or "something more" than just a poem, and in both cases the retaining of the original form would not seem to be excessively important. For example, one of the translators who have regarded haiku as most likely something less than a poem, is B. $\mathrm{H}$. Chamberlain who is said to have referred to the haiku as nothing more than "a litter of bricks, half-bricks in fact" (see Ueda 1991: 9). On the other hand, among those who view haiku as essentially more than "just a poem" belongs R. H. Blyth, for whom the measure of any poetry, or in fact, of any human activity, is Zen. ${ }^{31}$ The same kind of understanding is characteristic, incidentally, also of many Western haiku poets. To bring an example, for an American haiku poet J. W. Hackett haiku is "fundamentally existential, rather than literary", or, in other words, "primarily an experience, rather than a form of poetry", as well as "ultimately more than a form (or even a kind) of poetry: it is a Way — one of living awareness" (quot. Blyth 1998: 351, 352). Most of the time, however, also the advocates of Zen in haiku proceed from an understanding of haiku as a "short poem", generally also together with the articulation of the poem into three lines. ${ }^{32}$

\section{Conclusion}

In comparison to an original haiku, a translated haiku may allow itself some more freedom and still be acceptable as a (translated) haiku. However, the area within which a translated haiku can still be said to have retained the source text's "image", is rather difficult to define. The above has been an attempt to approach the formal boundary

${ }^{31}$ For Blyth's interpretation of Zen (and poetry, including haiku), see e.g. Blyth 1984, 1998; Franck 1978, Imamura 1995.

32 See, however, the previously quoted translation by F. L. Huntley of Bashō's cicada-haiku in which Huntley is said to have recognized "an arc of Zen" (Ueda 1991: 11). 
between "haiku-like" and "un-haiku-like" translations: observing the use of different syllable arrangement patterns of individual translators, there appear to exist significant differences in the preferences of different translators, as well as in the frequency with which one or another pattern is used. Translators, who try to retain the form of the original, tend to use (besides the 5-7-5 syllable pattern) two symmetrical patterns almost to the exclusion of others. More liberal translators, again, tend to use more different patterns and do not display as strong preferences towards any particular patterns as the more form-oriented translators do.

However, although the above attempt to understand the significance for a translated haiku of using different syllable organization patterns has been quite revealing with respect to the general dominants individual translators observe in their work, there are many questions left that need further investigation. For one, the above study does not reveal anything particular as to the influence of other parameters of haiku upon the preferences in the choice of syllable organization patterns in translated haiku. Another aspect worth studying is the possible replacement of the syllabic principle with the accentual one in haiku translations. In addition, one might also be curious to learn what would be the outcome if some other non-English translators were also included; what would be the results if a similar experiment were conducted with respect to Estonian or Russian translators only, i.e. are Masing's and Markova's results dependent on their individual styles only, or are there involved any general linguistic-cultural factors, etc.

\section{References}

Azadovskij, K. M.; Dyakonova, E. M. 1991. Bal'mont i Yaponiya. Moskva: Nauka.

Barthes, Roland 1975. S/Z. London: Cape.

Bashō, Matsuo 1996 [1689]. Oku no hosomichi / The Narrow Road to Oku. Translated by Donald Keene. Tokyo: Kodansha International.

Blyth, Reginald Horace 1984 [1963]. A History of Haiku. Volume One. From the Beginnings up to Issa. Tokyo: The Hokuseido Press.

- 1998 [1964]. A History of Haiku. Volume Two. From Issa up to the Present. Tokyo: The Hokuseido Press.

Bownas, Geoffrey; Thwaite, Anthony 1972 [1964]. The Penguin Book of Japanese Verse. Bungay: Penguin Books.

Chesterman, Andrew 2000 [1997]. Memes of Translation: The Spread of Ideas in Translation Theory. Amsterdam: John Benjamins. 
Donegan, Patricia; Ishibashi, Yoshie 1998. Chiyo-ni: Woman Haiku Master. Tokyo: Tuttle Publishing.

Franck, Frederick (ed.) 1978. Zen and Zen Classics by R. H. Blyth. New York: Vintage Books.

Holmes, James S. 1988. Translated!: Papers on Literary Translation and Translation Studies. Amsterdam: Rodopi.

Imamura, Kyoko 1995. The Integration of Eastern and Western Spirituality in Blyth's Zen in English Literature and Oriental Classics. In: Koji, Kawamoto; Yuan, Heh-Hsiang; Yoshihiro, Ohsawa (eds.), The Force of Vision 6: InterAsian Comparative Literature. Tokyo: International Comparative Literature Association, 151-159.

Kawamoto, Kōji 2000. The Poetics of Japanese Verse: Imagery, Structure, Meter. Tokyo: University of Tokyo Press.

Keene, Donald (ed.) 1996 [1955]. Anthology of Japanese Literature: from the earliest era to the mid-nineteenth century. Rutland: Charles E. Tuttle.

Lindström, Kati 1999. Eesti haiku pärastsõjaaegses "Loomingus”: žanri põhielementide määratlus ja tüpologiseerimise katse jaapani haiku taustal. (Unpublished seminar paper.) Tartu: Tartu Ülikool, Department of Semiotics.

Lotman, Mihhail; Lotman, Maria-Kristiina 2000. Tekst ja mälu (värsistruktuur ja selle semantika). In: Pärli, Ülle (ed.), Kultuuritekst ja traditsioonitekst. Tartu: Tartu Ülikool Kirjastus, 133-150.

Markova, Vera 1973. Hokku: Yaponskie trehstishiya. Moskva: Hudozhestvennaja literatura.

Masing, Uku 1997. Haikud: Jaapani luulet Uku Masingu tõlkes. Tartu: Ilmamaa.

— 1989. Kaks kirja haikude asjus. Akadeemia 5: 999-1002.

Mäger, Mart 1979. Luule ja lugeja. Tallinn: Eesti Raamat.

Oseko, Toshikaru 1990. Bashō no haiku / Bashō's Haiku: Literal Translations for Those Who Wish to Read the Original Japanese Text, With Grammatical Analysis and Explanatory Notes. Vol. 1. Tokyo.

Raud, Rein 1994. The Role of Poetry in Classical Japanese Literature: A Code and Discursivity Analysis. Tallinn: Eesti Humanitaarinstituut.

Swede, George 2000. Towards a Definition of the English Haiku. In: Swede, George; Brooks, Randy (eds.), Global Haiku: Twenty-Five Poets World-Wide. Oakville: Mosaic Press, 10-34.

Sütiste, Elin 2001. A Crow on a Bare Branch: A comparison of Matsuo Bashō's haiku "Kare-eda-ni..." and its English translations. Studia Humaniora Tartuensia 2.B.1. http://www.ut.ee/klassik/sht/2001/sytiste1.pdf

Tarasti, Eero 1992 [1990]. Johdatusta semiotiikkan. Helsinki: Gaudeamus.

Torop, Peeter 1995. Total'nyj perevod. Tartu: Tartu Ülikool Kirjastus.

Toury, Gideon 1993. "Translation of Literary Texts" vs. "Literary Translation": A Distinction Reconsidered. In: Tirkkonen-Condit, Sonja; Laffling, John (eds.), Recent Trends in Empirical Translation Research. Joensuu: University of Joensuu, 10-24.

Ueda, Makoto 1991. Bashō and His Interpreters: Selected Hokku with Commentary. Stanford: Stanford University Press.

Yamada-Bochynek, Yoriko 1985. Haiku East and West: A Semiogenetic Approach. Bochum: Studienverlag Dr. Norbert Brockmeyer. 
Yamane, Tadashi 1996. Chiyojo toki no uta / Chiyo-jo's Haiku Seasons. Trans. Donegan, Patricia; Ishibashi, Yoshie. Matto City.

Yasuda, Kenneth 1985 [1957]. The Japanese Haiku. Rutland: Charles E. Tuttle. Yasuda, Kenneth; Kuriyama, Shigeisha 1983. Haiku. In: Kodansha Encyclopedia of Japan, vol. 3. Tokyo: Kodansha, 78-82.

\section{Переводя семнадцать слогов}

В статье рассматриваются изменения формы при переводе японского хокку в иной языковой и культурный контекст, когда на поэтическую форму начинают влиять особенности и традиции другой культуры. Поэтому при переводах хокку часто пользуются некоторыми конвенциональными формами, в которых не соблюдаются все характерные для оригинального хокку черты. В то же время, чтобы перевод был узнаваемым как хокку, он все же должен сохранить и определенные формальные черты хокку. Наши наблюдения основываются на 420 переводах хокку. В центре внимания находится количество слогов и параметры их распределения по строкам, на основе которых предлагаются разные модели упорядочивания слогов в переводах. Дается предварительная классификация типов переводных хокку по линии ориентированности на форму.

\section{Tõlkides seitsetteist silpi}

Käesolev artikkel käsitleb vormimuutusi, mis tekivad jaapani haiku tõlkimisel teise keelelis-kultuurilisse konteksti. Kuna tõlkimisel hakkavad luulevormi mõjutama teise kultuuri iseärasused ning traditsioonid, kasutatakse haiku edastamisel sageli teatud kokkuleppelisi vorme, mis ei järgi kõiki algupärasele haikule iseloomulikke jooni. Samas, selleks et tõlkehaiku oleks käsitletav sama vormina kui algupärane haiku, peab ta siiski säilitama teatud tunnused, mis on iseloomulikud ka algupärasele vormile. Artiklis tehtavad vaatlused põhinevad käesoleva töö tarbeks kogutud 420 tõlkehaikul. Tähelepanu keskmes on silpide arvu ja ridadesse paigutumise parameetrid, mille alusel pakutakse välja tõlkehaikude erinevaid silbikorrastusmudeleid. Mudelite üldise ja individuaalse esinemissageduse alusel esitatakse esialgne iseloomustus, milliseid tõlgitud haikude tüüpe võiks pidada rohkem vormile orienteerituks kui teisi. 